\title{
SURGICAL OUTCOMES OF VARICOSE VEINS AT UNIVERSAL COLLEGE OF MEDICAL SCIENCES, BHAIRAHAWA,NEPAL.
}

Santosh Shah ${ }^{1}$, Sumod Koirala ${ }^{2}$, Saroj Pradhan ${ }^{2}$ Ashok Pradhan ${ }^{2}$

\section{ABSTRACT}

\section{INTRODUCTION:}

This study was conducted to analyse the surgical outcomes of varicose vein at Universal College of Medical Sciences (UCMS), Bhairahawa.

\section{MATERIALS AND METHODS:}

A hospital based prospective study done at UCMS, Bhairahwa, Nepal over the period of one year, where all the patients who had lower limb varicose vein underwent surgery were analyzed.

\section{RESULTS:}

A total of 25 cases of varicose vein were operated at UCMS from August 2015 to July 2016. The post-operative complications like pain, wound abscess, aching, itching were minimal.

\section{CONCLUSION:}

Surgical treatment by SFJ ligation with stripping long and short saphenous vein is an established effective treatment of varicose vein in our center with minimal post-operative complications.

\section{KEYWORDS:}

Varicose vein, stripping long and short saphenous vein.

1. Asst. Professor, Department of Surgery, Cardiothoracic \& Vascular Surgery (CTVS), Universal College of Medical Sciences, Bhairahawa, Nepal

2. PG Resident, Department of Surgery, Universal College of Medical Sciences, Bhairahawa, Nepal

\author{
For correspondence: \\ Dr. Santosh Shah, M.Ch(CTVS) \\ Asst. Professor, \\ Cardiothoracic \& Vascular Surgery (CTVS) \\ Department of Surgery, \\ Universal College of Medical Sciences, \\ Bhairahawa, Nepal \\ Email:santshah@hotmail.com
}




\section{INTRODUCTION:}

According to the World Health Organization, varicosities are defined as saccular or cylindrical widened superficial veins, where the widening may be circumscribed or segmental. In general, the dilatation of the veins is associated with tortousities .Varicose veins are common in females but onset of the disease is earlier in males. The incidence is about 20 $25 \%$ of the adult female population and $10-15 \%$ of men in western countries ${ }^{1}$.

Primary varicose veins:

They occur as result of congenital weakness in the vessel wall. It can also be due to muscular weakness or due to congenital absence of valves. Primary varicosity can also be familial. These factors, in addition to prolonged standing, help in the development of the varicose veins. Varicosity is the penalty for verticality against gravity. Klippel -Trenaunay syndrome is a congenital venous abnormality wherein superficial and deep veins do not have any valves. It is also called as " valveless syndrome"

Secondary varicose veins:

Women are more prone for varicose veins because of the following reasons:

1. Pregnancy and pelvic tumours.

2. Pills (oral contraceptive pills) alter the viscosity of blood.

3. Progesterone dilates vessel wall.

4. Congenital arterio -venous fistula increases blood flow and increases venous pressure.

5. Deep vein thrombosis can result in destruction of valves resulting in varicose veins.

Spider veins are similar to varicose veins, but they are smaller. They are often red or blue and are closer to the surface of the skin than varicose veins. They can look like tree branches and spider webs with their short jagged lines. Spider veins can be found on the legs and face. They can cover either a very small or very large area of skin. Chronic venous insufficiency may result in feeling of heaviness, tendency for swelling, leg pain, and leg ulcer. The prevalence of varicose veins in different countries is different.

\section{MATERIALS AND METHODS:}

All patients of varicose veins of lower limb who had attended the OPD of cardiovascular and thoracic surgery department, UCMS, Bhairahawa, from August 2015 to July 2016 were included in this study. A total of 27 patients had attended the OPD. Age and sex wise prevalence has been shown in the column graph below. There was greater predisposition of some of the occupations to the disease which have been shown in table no 2 . All the patients were examined clinically. Necessary tests and investigations were done. Diagnosis was further confirmed with duplex ultrasonography. Though different types of treatment are available, SFJ(sapheno femoral junction) ligation and LSV (long saphenous vein) stripping are the commonest surgical procedures in this study. The incidence is more in males, consisting 70.37\%; and in females $29.63 \%$.In this study right side is affected in $33.33 \%$ and left $33.33 \%$. Bilateral limbs are affected in $33.33 \%$. In the operated cases, males comprised of $76 \%$ and females $24 \%$.In the post-operative period, no any complications like haemorrhage, haematoma, or infection were noted.

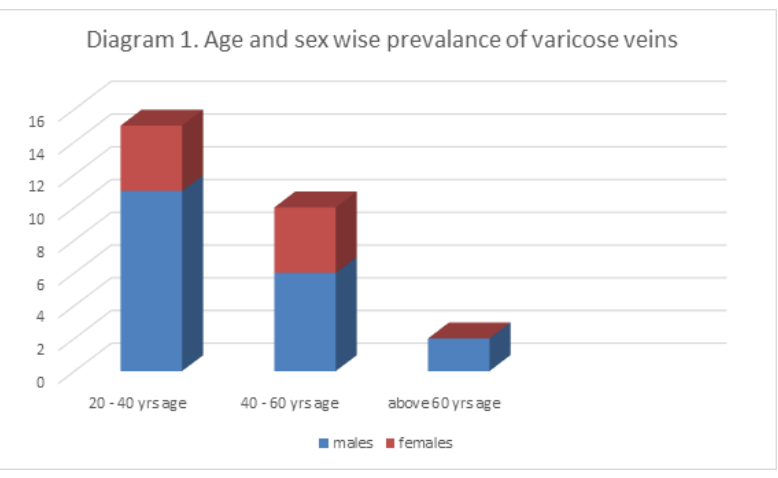

Table: 1 Surgical procedure for lower limb varicose veins

\begin{tabular}{|l|l|}
\hline Name of the surgical procedure undertaken & Number of cases \\
\hline $\begin{array}{l}\text { SFJ flush ligation + L SV stripping + Local } \\
\text { avulsion }\end{array}$ & 15 \\
\hline Ligation of varicosed vein and stripping & 5 \\
\hline SSV local avulsion + Ligation of perforators & 1 \\
\hline SSV ligation + Local avulsion & 1 \\
\hline Trendelenburg's operation & 1 \\
\hline SFJ flush ligation + Local avulsion & 1 \\
\hline Multiple 8 tab phlebotomy & 1 \\
\hline
\end{tabular}

Table: 2 - Occupation wise prevalence of lower limb varicose veins

\begin{tabular}{|l|l|}
\hline Patient's occupation & Number of cases \\
\hline cook & 9 \\
\hline Security guard/Police man & 7 \\
\hline Farmer & 4 \\
\hline Others & 7 \\
\hline
\end{tabular}




\section{RESULTS:}

A total of 27 cases of varicose veins of the lower limb had attended in the out-patient department of cardiovascular and thoracic surgery, UCMS, Bhairahawa; and 25 cases were operated from 2015 to 2016. The post-operative complications like pain, wound abscess, aching, itching were minimal.

\section{DISCUSSION:}

Disease of the venous system is a major problem affecting western societies resulting in considerable morbidity in the population and cost to the health services. Also, in many countries, varicose veins are probably the commonest disorder presenting to the general surgeons ${ }^{2}$.

The surgical treatment of varicose veins can be achieved in different ways like:-

i) Trendelenburg's operation + stripping + phlebectomies of remaining varicosities.

ii) Trendenlenberg's operation + stripping + subfascialligation.

iii) Sub-fascial ligation.

iv) Endovascular laser treatment (EVLT).

v) Transilluminated powered phlebectomy (TIPP).

vi) Radio-frequency ablation (RFA) waves to close the varicose veins.

vii) Catheter-assisted ablation of veins.

We had not done SFJ ligation only because recurrences of varicose veins are very high. Majority of the patients had SFJ ligation and LSV stripping. But it is reported that Trendenlenberg's operation with subfascial ligation has given good results ${ }^{3}$.Glass has recently proposed that recurrence of varicose veins may be the result of 'neovascularisation' of the ligated long saphenous vein (LSV) ${ }^{4}$.

This may be true when the LSV is left in situ, but it does not explain the incidence of reflux where the LSV is stripped. Stripping the LSV to the upper calf does not result in a higher incidence of injury to the saphenous nerve ${ }^{5}$. In the postoperative period, LSV reflux is more completely abolished by combining LSV stripping with SFJ ligation. SFJ ligation is the commonest cause of recurrence ${ }^{6}$. The principal outcome measures were abolition of reflux in the treated segment of the great saphenous vein(technical success) and improvement in disease-specific quality of life 3 months after treatment (clinical success).Therefore we recommend bilateral operation to some patients when indicated. Although some recurrence of varicose veins is frequent at 10-years after operation, surgery provides long-term relief of symptoms in the great majority of patients ${ }^{7}$.The surgical procedures we had undertaken is represented in Table no: 1 .

\section{CONCLUSION:}

Varicose vein is a chronic morbid condition. Though newer techniques like Endovenous Laser Treatment (EVLT), Transilluminated Powered Phlebectomy, and RadioFrequency Ablation (RFA) are available, surgical treatment by stripping of the long and short saphenous veins with the ligation of SFJ is an established effective treatment of varicose veins in our center. Patients were followed-up regularly in the out-patient department for detection of any recurrent or residual varicosities. The Framingham Study of Boston University suggests that increased physical activity and weight control may help to prevent varicose veins among adults at high risk and reduce the overall risk of atherosclerotic cardiovascular disease as well ${ }^{8}$.

\section{REFERENCES:}

1. Callam MG. Epidemiology of Varicose Veins. Br J Surg1994; 81(2):167-73

2. Evans C, Fowkes FG, Ruckley CV, Lee A. Prevalence of Varicose Veinsand Chronic Venous Insufficiency in men and women in the general population: Edinburgh Vein Study. JEpidemiol Community Health 1999; 53: 149-53.

3. Goutham RK, RN Satish Bharadwaj, Gurjit S. Varicose Veins: clinical presentation and surgical management. Ind J Sur 2009; 71(3): $117-20$

4. Darwood RJ, Thievacumar N, Dellagrammaticas $D$ et al Randomised Clinical Trial comparing endovenous laser ablation with surgery for the treatment of primary great Saphenous Varicose Veins. BJSurg2008; 95: 294-301.

5. Browse NL, Burnand KG, Thomas ML. Diseases of the Veins: Pathology, diagnosis and treatment. London: Edward Arnold. 1988.p202

6. Sarin S, Scurr JH, Coleride PD. Assesement of stripping the long saphanous vein in the treatment of primary Varicose Veins. $\mathrm{Br}$ JSurg1992; 79: 889-93.

7. Compbell WB, Vijay KA, Collin TW. Outcome of varicose vein surgeryat 10 years: Clinical findings, symptoms and patient satisfaction. Ann Royal Col Surg2003; 85(1):52-7

8. Brand FN, Dannenberg AL, Abbott RD, Kannel WB. Epidemiology of the varicose veins: the Framingham study. Ann JPrev Med 1988;4(2): 96-101. 